\begin{tabular}{l}
\hline OPEN O ACCESS Freely available online \\
http://www.banglajol.info/index.php/BJID/index \\
Original Article \\
Bangladesh Journal of Infectious Diseases \\
December 2014, Volume 1, Number 2 \\
ISSN (online) 2411-670X \\
ISSN (Print) 2411-4820
\end{tabular}

\title{
Frequency and Distribution of Gram Negative Bacteria among Hospital and Community Acquired UTI Patients
}

\author{
Md. Badrul Islam¹, Md. Abdullah Yusuf ${ }^{2}$, Md. Shahjahan Chowdhury ${ }^{3}$, AFM Arshaedi Sattar ${ }^{4}$, Samia Afrin ${ }^{5}$ \\ ${ }^{1}$ Associate Professor, Department of Microbiology, Dhaka National Medical College, Dhaka, Bangladesh; ${ }^{2}$ Assistant Professor, \\ Department of Microbiology, National Institute of Neurosciences \& Hospital, Dhaka, Bangladesh; ${ }^{3}$ Associate Professor, Department \\ of Pathology, Dhaka National Medical College, Dhaka, Bangladesh; ${ }^{4}$ Assistant Professor, Department of Microbiology, National \\ Institute of Neurosciences \& Hospital, Dhaka, Bangladesh; ${ }^{5}$ Assistant Professor, Department of Microbiology, ZH Sikder Woman's \\ Medical College, Dhaka, Bangladesh
}

[Received: 1 January 2014; Accepted: 15 March 2014; Published: 2 November 2014]

\begin{abstract}
Gram negative bacteria create a great problem during the treatment of urinary tract infection patients. This study was undertaken to determine the frequency and distribution of Gram negative bacteria among the UTI patients. This cross sectional study was carried out in the Department of Microbiology at Sir Salimullah Medical College, Dhaka from June 2007 to May 2008 for a period of 1(one) year. All the patients presented with the clinically suspected UTI at any age with both sexes were selected as study population. Patients who were hospitalized for at least 2 days or more received different antibiotics were designated as hospital acquired UTI; on the other hand patients who were attended in OPD for the first time were considered as community acquired UTI patients. All urine samples were inoculated in Blood agar and MacConkeys agar media. Gram negative bacteria were isolated and identified by colony morphology, Gram staining and biochemical tests. A total of 220 urine samples were collected from patients suspected to urinary tract infections of which 116 samples were from hospitalized patients and 104 samples were from community patients. Among 220 samples, 132(60.0\%) Gram negative bacteria were isolated of which 88(66.7\%) isolates were from hospitalized acquired UTI and 44(33.3\%) bacteria were isolated from community acquired UTI patients. The difference was statistically significant $(\mathrm{p}=0.0001)$. In hospitalized patients out of 88(75.9\%) isolated Gram negative bacteria, 67(76.1\%) isolates were Escherichia coli, 10(11.4\%) isolates were Klebsiella species, 5(5.7\%) isolates were Proteus species and 6(6.8\%) isolates were Pseudomonas species. Among the isolated bacteria $44(42.3 \%)$ bacterial isolates were from community patients of which $36(81.8 \%)$ isolates were Escherichia coli, 4(9.1\%) isolates were Klebsiella species, 2(4.5\%) isolates were Proteus species and $2(4.5 \%)$ bacteria were Pseudomonas species. In the present study, it was observed that considerable numbers of Gram negative bacteria were detected from urinary tract infection cases. [Bangladesh J Infect Dis $2014 ; 1(2): 24-26]$
\end{abstract}

Keywords: Gram Negative Bacteria, Hospital Acquired UTI ; Community Acquired UTI

[How to Cite this article: Islam MB, Yusuf MA, Chowdhury MS, Sattar AFMA, Afrin S. Frequency and Distribution of Gram Negative Bacteria among Hospital and Community Acquired UTI Patients. Bangladesh J Infect Dis 2014;1(2):24-26]

Corresponding author: Md. Badrul Islam, Associate Professor, Department of Microbiology, Dhaka National Medical College, Dhaka, Bangladesh; Email: badrulislam19@gmail.com; Cell no.: +8801670738692

Conflict of Interest: Authors have declared no conflict of interest.

Contributions to authors: MBI, AFMAS \& ABL have contributed from protocol preparation to manuscript writing as well as in data collection. MBI, MSC have prepared and revised the manuscript as well as data analysis. 


\section{Introduction}

Urinary tract infection is now a major problem in both hospital and community level cases ${ }^{1}$. Most commonly found bacteria are Escherichia coli, Klebsiella pneumoniae, Proteus species, Salmonella species, other members of Enterobacteriaceae and Pseudomonas aeruginosa ${ }^{2-5}$. Long term antibiotic exposure, prolonged ICU stay, severe illness, nursing home residents, catheterization or instrumentation are the major risk, factor for colonization of different hospital acquired bacteria ${ }^{6}$. Some bacteria can cause both community and hospital acquired infection which can be very difficult to treat with common drugs $^{3}$. Therefore, this study was undertaken to determine the frequency and distribution of Gram negative bacteria among the hospital and community acquired UTI patients.

\section{Methodology}

This cross sectional study was carried out in the Department of Microbiology at Sir Salimullah Medical College, Dhaka from June 2007 to May 2008 for a period of 1 (one) year. All the patients presented with the clinically suspected UTI at any age with both sexes were selected as study population. Patients who were hospitalized for at least 2 days or more received different antibiotics were designated as hospital acquired UTI; on the other hand patients who were attended in OPD for the first time were considered as community acquired UTI patients. Urine was collected from all patients in a sterile container. All urine samples were inoculated in Blood agar and MacConkeys agar media. All the plates were incubated at $37^{\circ} \mathrm{C}$ aerobically for 24 hours and Gram negative bacteria were isolated and identified by colony morphology, Gram staining and biochemical tests. Data were collected as per pre-designed data collection form. Data were analyzed by Statistical Package for Social Science (SPSS), Version -13. The qualitative data were expressed as frequency and percentage. The association was measured by Chi-square test. In $95 \%$ confidence interval $\mathrm{P}$ value less than 0.05 was taken as level of significance.

\section{Result}

A total of 220 urine samples were collected from patients suspected to urinary tract infections of which 116 samples were from hospitalized patients and 104 samples were from community patients. Among 220 samples, 132(60.0\%) Gram negative bacteria were isolated of which $88(66.7 \%)$ isolates were from hospitalized acquired UTI and 44(33.3\%) bacteria were isolated from community acquired UTI patients. The difference was statistically significant $(\mathrm{p}=0.0001)$ (Table 1$)$.

Table 1: Distribution of bacteria of hospitalized and community acquired UTI

\begin{tabular}{lccc}
\hline UTI & \multicolumn{2}{c}{ Culture } & Total \\
& Positive & Negative & \\
\hline HA & $88(66.7)$ & $28((31.8)$ & $116(52.7)$ \\
CA & $44(33.3)$ & $60(68.2)$ & $104(47.3)$ \\
Total & $132(100.0)$ & $88(100.0)$ & $220(100.0)$ \\
\hline
\end{tabular}

*figure within parenthesis indicates percentage; Chi-square test was done to see the level of significance; $p$ value $=0.0001$; $\mathrm{HA}=$ Hospital acquired; $\mathrm{CA}=$ Community acquired

In hospitalized patients out of $88(75.9 \%)$ isolated Gram negative bacteria, 67(76.1\%) isolates were Escherichia coli, 10(11.4\%) isolates were Klebsiella species, 5(5.7\%) isolates were Proteus species and $6(6.8 \%)$ isolates were Pseudomonas species. Among the isolated bacteria 44(42.3\%) bacterial isolates were from community patients of which 36(81.8\%) isolates were Escherichia coli, 4(9.1\%) isolates were Klebsiella species, $2(4.5 \%)$ isolates were Proteus species and 2(4.5\%) bacteria were Pseudomonas species (Table 2).

Table 2: Distribution of isolated bacteria among hospitalized and community acquired UTI

\begin{tabular}{lccc}
\hline \multirow{2}{*}{ Bacteria Name } & \multicolumn{2}{c}{ UTI } & Total \\
\cline { 2 - 3 } & HA & CA & \\
\hline E. coli & $67(76.1)$ & $36(81.9)$ & 103 \\
Klebsiella & $10(11.4)$ & $4(9.1)$ & 14 \\
Proteus spp. & $5(5.7)$ & $2(4.5)$ & 7 \\
Pseudomonas & $6(6.8)$ & $2(4.5)$ & 8 \\
Total & $88(75.9)$ & $44(42.3)$ & 132 \\
\hline
\end{tabular}

*HA=Hospital acquired; $\mathrm{CA}=$ Community acquired; $\mathrm{P}$

value $=0.900$; figure within parenthesis indicates percentage

\section{Discussion}

ESBLs have become widespread throughout the world ${ }^{5}$ and are now found in a significant percentage of Escherichia coli and Klebsiella pneumoniae strains in certain countries ${ }^{7}$. ESBLs are responsible for resistance to many classes of antibiotics resulting in treatment failure ${ }^{8}$. In this study, out of 220 urine samples, $132(60 \%)$ bacterial strains were isolated. Of them, $88 \quad(75.9 \%)$ were from hospitalized patients and 44(42.3\%) from community patients. In the hospitalized patients, total 116 urine samples were studied. Of them, 88 
(75.86\%) bacterial strains were isolated and 28 $(31.82 \%)$ strains were ESBL producers. In a study in Bangladesh, $32.33 \%$, strains were reported as ESBL producers in urine samples ${ }^{8}$. The findings of the present study were in accordance with the result of this study. In the present study, the ESBL producers are more among the organisms isolated from hospitalized patients than the community patients. The reason might be due to hospitalized patients were recruited after 2 days or more of hospitalization and all the patients received different antibiotics ${ }^{8}$.

Among the community patients, total 104 urine samples were collected of which 44(42.3\%), bacterial strains were isolated and $3(6.8 \%)$ strains were ESBL producers. This is very high frequency as ESBLs are rarely seen in the community patients. This is probably due to reason that in society extended spectrum cephalosporins are used indiscriminately in community patients. In this study majority bacterial isolates from hospitalized patients are isolates Escherichia coli $(76.1 \%)$. The finding of the study agrees with the result of different studies ${ }^{3,5-6}$. In another study it has been reported that $E$. coli is the most predominate bacteria in both community acquired and hospital acquired $\mathrm{UTI}^{4}$ which is consistent with the present study. Interestingly Klebsiella species are the second most common bacteria infecting both community acquired $(4.5 \%)$ and hospital acquired $(5.7 \%)$ UTI.

In this study Proteus species and Pseudomonas species are also isolated from both the community acquired and hospital acquired UTI. It has been previously reported that Pseudomonas species is the hospital acquired bacteria especially catheterized patients ${ }^{7}$. Regarding this context Pseudomonas species is also isolated from this study group. Therefore, the isolated bacteria from UTI patients are changing.

\section{Conclusion}

In conclusion it has been found that the most common isolated Gram negative bacteria is still Escherichia coli that causes both community acquired and hospital acquired UTI with a very high rate. Klebsiella species, Pseudomonas species and Proteus species also isolated from all types of UTI patients. Therefore, routine urine culture should be performed to see the frequency of bacteria causing UTI; furthermore, antimicrobial sensitivity should be carried out to see the resistant pattern of antibiotic towards these bacteria.

\section{References}

1. Hooton TM, Bradley SF, Cardenas DD, Colgan R, Geerlings SE, Rice JC, et al. Diagnosis, prevention, and treatment of catheter-associated urinary tract infection in adults: 2009 International Clinical Practice Guidelines from the Infectious Diseases Society of America. Clin Infect Dis 2010;50(5):625-663

2. Akram M, Shahid M, Khan AU. Etiology and antibiotic resistance patterns of community-acquired urinary tract infections in JNMC Hospital Aligarh, India. Annals of Clin Microbiol Antimicrob 2007;6(1):4

3. Ronald A. The etiology of urinary tract infection: traditional and emerging pathogens. American $\mathrm{J}$ Med 2002;113(1):14-19

4. Foxman B, Barlow R, D'Arcy H, Gillespie B, Sobel JD. Urinary tract infection: self-reported incidence and associated costs. Ann Epidemiology 2000;10(8):509-515

5. Gupta K, Sahm DF, Mayfield D, Stamm WE. Antimicrobial resistance among uropathogens that cause community-acquired urinary tract infections in women: a nationwide analysis. Clin Infect Dis 2001;33(1):89-94

6. National Committee for Clinical Laboratory Standards. Performance standards for antimicrobial susceptibility testing. Fourteenth international supplement, approved standard M 100 SI4, NCCLS, Wayne, PA, 2004

7. Ahmed I, Salam A. Extended Spectrum |3-lactamases and Bacterial Resistance. Pak J Med Sci 2002;18(2):151-55

8. Shah A A, Hasan F, Ahrned S and Hameed A. Prevalence of extended spectrum p-lactamases in nosocomial and outpatients. Pak J Med Sci. 2003; 19(3): 187-91 